\title{
Relationships between Authentic Leadership, Moral Courage, and Ethical and Pro-Social Behaviors
}

\author{
Sean T. Hannah, Bruce J. Avolio, and Fred O. Walumbwa
}

\begin{abstract}
Organizations constitute morally-complex environments, requiring organization members to possess levels of moral courage sufficient to promote their ethical action, while refraining from unethical actions when faced with temptations or pressures. Using a sample drawn from a military context, we explored the antecedents and consequences of moral courage. Results from this four-month field study demonstrated that authentic leadership was positively related to followers' displays of moral courage. Further, followers' moral courage fully mediated the effects of authentic leadership on followers' ethical and pro-social behaviors. Theoretical and practical implications for further integrating the work on moral courage, authentic leadership and ethics are discussed.
\end{abstract}

$\mathrm{M}$ ODERN ORGANIZATIONS HAVE BEEN CHARACTERIZED as morally complex environments that impose significant ethical demands and challenges on organizational actors. Researchers have suggested that to meet these demands individuals require high levels of character in order to promote ethical behavior (Hunter, 2003). Yet, while a rich body of theoretical work exists in the field of ethics in general, empirical research assessing ethical behavior and the individual and contextual factors that give rise to ethical behavior in organizations is minimal. Existing empirical ethics research has focused predominantly on aspects of ethical cognition and judgment versus ethical behavior (Reynolds, 2006), as is evident in recent ethics literature reviews (Tenbrunsel \& Smith-Crowe, 2008; Treviño, Weaver, \& Reynolds, 2006).

The accumulated evidence leaves further work needed to determine what factors drive individuals beyond moral judgments to enact actual ethical behaviors. In response, Hannah, Avolio, and May (2011) developed a theory titled moral conation, the impetus to act with moral purpose, which these authors proposed to stem from moral courage, moral efficacy, and moral psychological ownership. In the current study, we focus on the component of moral courage and assess its antecedents and behavioral outcomes in a field study conducted over a four month period.

Sekerka and Bagozzi (2007: 135) defined moral courage as "the ability to use inner principles to do what is good for others, regardless of threat to self, as a matter of practice." Kidder defined moral courage as "a commitment to moral principles, an awareness of the danger involved in supporting those principles, and a willing endurance of that danger" (Kidder, 2005: 7). Both definitions denote overcoming danger or risk to willingly uphold personal moral principles. We will integrate below 
these and other definitions in seeking a richer understanding of what constitutes moral courage.

We focused on moral courage because we believe it is a critical factor in determining whether actors will step up and act in line with their judgments and beliefs. Indeed, research has shown that ethical judgments are only weakly related to actual ethical behavior (Bebeau, 2002; Blasi, 1980; Treviño \& Youngblood, 1990). In a review of multiple studies, Rest, Narvaez, Bebeau, and Thoma (1999) reported that the most commonly used measure of cognitive moral judgment capacity, the Defining Issues Test, typically explains just 20 percent of the variance in actual ethical behavior. Consistent with Hannah, Avolio et al. (2011) and others (e.g., Kidder, 2005; Sekerka \& Bagozzi, 2007), we suggest that the conation to act ethically, as represented by moral courage, will help explain why one actor will step up and act while another who arrives at the same ethical judgment in the same situation will stand by and fail to act.

Despite the theoretical arguments for the importance of moral courage in promoting ethical behavior (Kidder, 2005; Kidder \& Bracy, 2001), prior empirical work (e.g., Sekerka, Bagozzi, \& Charnigo, 2009; Woodard \& Pury, 2007) has two primary limitations. First, there is an absence of research testing whether moral courage predicts actual ethical behaviors. Second, testing of potential antecedents to moral courage is minimal, limiting the field's understanding of how moral courage is bolstered or developed. We intend to begin addressing these limitations in the current study.

Our first goal was to conduct what is perhaps the first empirical test of moral courage in predicting ethical and pro-social behaviors. Treviño, Weaver, and Reynolds defined ethical behavior as "those acts that reach some minimal moral standard and are therefore not unethical, such as honesty or obeying the law" (Treviño et al., 2006: 952). Consistent with Bandura (1991, 1999), this conceptualization includes both the commission of ethical actions as well as restraint from unethical acts. Monin, Pizarro, and Beer (2007) proposed that being ethical requires not only acting in pursuit of right over wrong, but the inner fortitude to restrain from action when faced with moral temptations. This is consistent with the Stoic view of ethics and moral courage (Putman, 2010), as well as a review of behavioral ethics in organizations (Treviño et al., 2006) that identified that awareness, judgment, and disengagement are important determinants of ethical/unethical behavior.

Further, we introduce pro-social behavior in this study to refer to behaviors that go beyond specified role requirements, and that exhibit taking action to protect the organization and coworkers interests. This includes positive acts carried out to produce and maintain the well-being and integrity of others, such as helping coworkers, sharing, cooperating, and respecting and treating coworkers with dignity (Brief \& Motowidlo, 1986). This perspective views pro-social behavior as deliberate behavior that is influenced by one's moral courage, as moral courage entails invoking inner standards to do what is good for others (Sekerka \& Bagozzi, 2007). We know of no research to date that has investigated the relationship between moral courage and pro-social behavior. 
Second, researchers have proposed that courage is a somewhat malleable state that is influenced by contextual factors in organizations (Hannah, Sweeney, \& Lester, 2010), and have proposed that leadership is one contextual factor that may be particularly powerful in bolstering followers' moral courage (Lester, Vogelgesang, Hannah, \& Kimmey, 2010; Walker \& Henning, 2004). These authors drew on social cognitive theory (SCT; Bandura, 1999, 2001) to explain the proposed connections. Specifically, SCT examines the reciprocal causation between the person, their behavior, and their environment in terms of explaining actions taken (Bandura, 1999, 2001). SCT serves to explain individuals' capacity to control the nature and quality of their life through exercising individual agency — as in performing ethical acts prompted by moral courage to right a wrong-such that they are not just a product of, but also a producer of their environment. Due to reciprocal causation, the environment in turn influences the extent that individuals build and exercise agency through mechanisms such as influencing levels of courage, efficacy, and a psychological sense of ownership or responsibility. As salient factors in organizational environments, we suggest leaders impose significant influence on followers' thoughts and behaviors related to moral courage and ethical behavior (Lester et al., 2010).

Using SCT as a guiding framework to link the constructs examined in the current study, we investigate the links between authentic leadership and follower moral courage and subsequent ethical and pro-social behaviors. Authentic leadership has been defined as "a pattern of leader behavior that draws upon and promotes both positive psychological capacities and a positive ethical climate, to foster greater self-awareness, an internalized moral perspective, balanced processing of information, and relational transparency on the part of leaders working with followers, fostering positive self-development" (Walumbwa, Avolio, Gardner, Wernsing, \& Peterson, 2008: 94). Authentic leaders are perceived by followers as being high in moral perspective and self-awareness, as well as practicing balanced and fair decision-making, openness, and transparency (Avolio \& Luthans, 2006). These acts should not only have social learning effects, but also influence the context in ways that support followers' moral courage.

Authentic leadership has been proposed to influence follower ethical behaviors, in addition to other positive outcomes such as well-being (Avolio, Gardner, Walumbwa, Luthans, \& May, 2004; Gardner, Avolio, Luthans, May, \& Walumbwa, 2005; Ilies, Morgeson, \& Nahrgang, 2005). Brown and Mitchell (2010) surmised that because of its "strong emphasis on the ethical dimension of leaders, future research linking authentic leadership to important ethics-related outcomes is promising." Yet these proposed links to ethics have not been tested, and are the focus of the present study.

\section{THEORY AND HYPOTHESIS DEVELOPMENT}

\section{A Social Cognitive Theory Approach to Moral Courage}

The reciprocal causation between the person (cognition and other personal factors), behavior, and the environment noted in SCT provides an effective framework with which to consider moral courage. Figure 1 displays the triadic SCT model proposed by Bandura $(1991,2001)$ with the constructs of the current study superimposed. As 
illustrated, moral courage is a personal factor and influences ethical behavior, with those behaviors then influencing the actor's engagement with, and impacts on, his or her environment. Through observing their behaviors and the perceived positive effects made on the environment, actors can then develop moral courage over time. SCT proposes that personal factors such as courage influence the extent individuals exercise control and influence over their lives based on whether they interpret their experiences and regulate their behaviors in ways to be an active producer as opposed to only a product of their environment (Bandura, 2001).

Although individuals can affect their environment, Bandura suggests that the environment reciprocally influences moral cognition and personal factors in two ways: "Social influences affect the operation of the self-system ... [and] . . by providing collective support for adherence to moral standards" (Bandura, 1991: 20). As key aspects of social environs, leaders can influence both processes. First, accumulated research has shown that leaders have a powerful influence on followers' self-systems (see Lord \& Brown, 2004 for overview), with one primary avenue of influence being through social learning (Bandura, 1977, 1991, 2001). It has been argued that social learning through observing moral exemplars will enhance observers' moral cognitions and also their moral courage (Walker \& Henning, 2004). Second, leaders can influence the level of collective support for morality observed in the environment. Based on the SCT model (Figure 1), such an environment can directly influence the moral courage of the follower, and then mediated through moral courage, influence his or her ethical behavior. A leader, for example, can create an open, transparent and safe culture where discussing and reporting ethical issues is rewarded or even demanded, thereby bolstering followers' moral courage, which in turn, positively influences the likelihood of the follower behaving ethically.

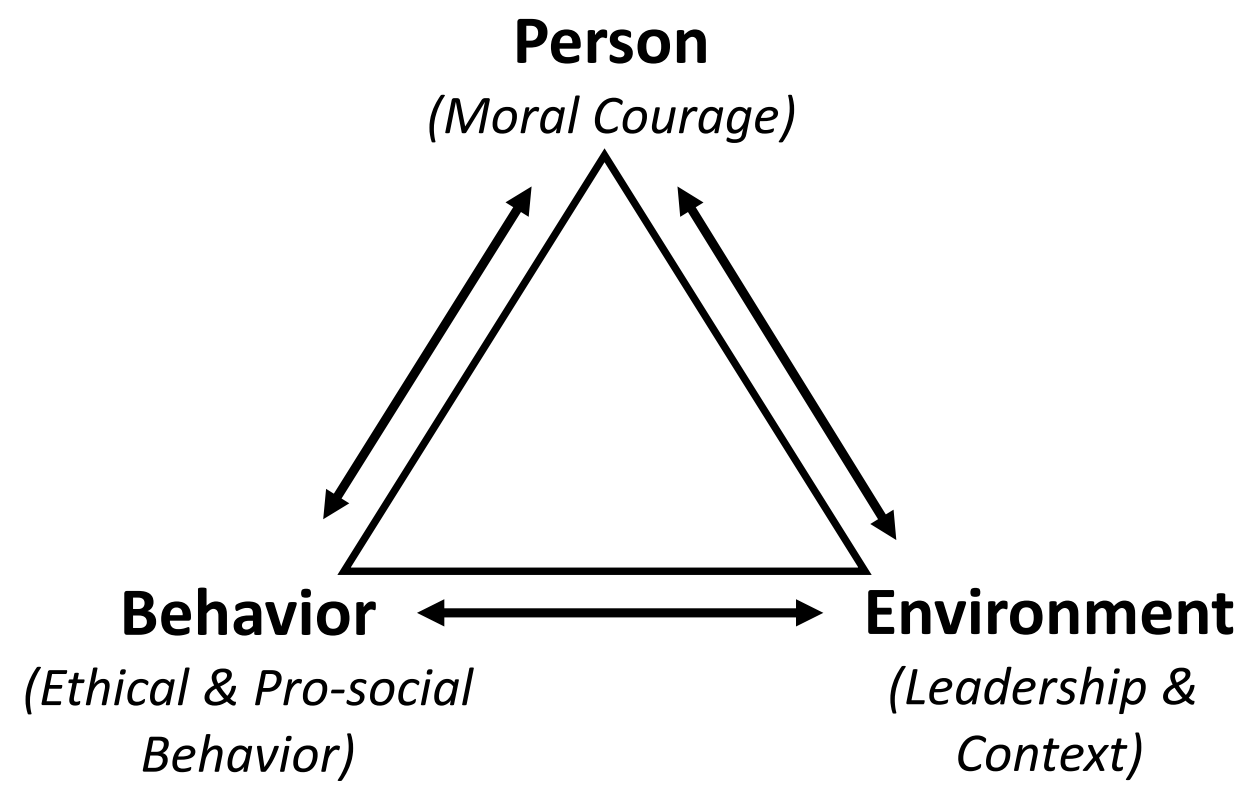

Figure 1: A Social Cognitive Model of Moral Courage 


\section{Moral Courage and Follower Ethical and Pro-social Behavior}

We begin our hypothesis development focused on the person-behavior linkage of the SCT model shown in Figure 1. We start by further defining moral courage and then by theoretically linking moral courage to followers' ethical and pro-social behavior. Next, we turn our focus to the environment-person linkage of the SCT model shown in Figure 1 to develop a theoretical basis for leadership in influencing follower moral courage. We also examine how moral courage mediates the effects of leadership on followers' behaviors.

\section{Operationalizing Moral Courage}

It is important to recognize that researchers have provided various definitions of courage (moral or otherwise) and have in some cases empirically differentiated ways of defining and measuring moral courage. For example, some researchers have defined moral courage as a character strength or trait that provides followers with an inner psychological strength to draw from when facing tough ethical choices (e.g., Kidder \& Bracy, 2001; Miller, 2002; Peterson \& Seligman, 2004). Other authors have argued that moral courage is formed in situ whereby the personal agency required to act when faced with ethical challenges or threats is developed (e.g., Sekerka \& Bagozzi, 2007). In this case, moral courage is not a static trait or property, but is viewed as being a malleable individual property where different levels of moral courage are created depending on the influence of situational factors on the actor's psychological processes (Hannah, Avolio, et al., 2011; Hannah \& Avolio, 2010).

A third approach from Aristotle suggests that moral courage is both a means and an ends, and therefore must be evidenced in behavior. Aristotle proposed that character "is that which reveals choice, shows what sort of thing a man chooses or avoids in circumstances where the choice is not obvious, so those speeches convey no character in which there is nothing whatever which the speaker chooses or avoids" (Nussbaum, 1992: 117). Aristotle proposed that character such as courage is composed of habits which are formed through repetitious acts (Putman, 2010).

While Aristotle viewed courage as active and malleable, a fourth view of courage stems from the Stoic tradition and the philosopher Epictetus, who proposed that moral courage is often choosing not to act under pressure. As noted by Putman (2010: 15), to the Stoics, "not doing anything can be an act of cowardice, but saying "no" can also be an act of real courage." From this perspective, maintaining moral agency often requires the moral courage to resist temptations and social pressures (Monin et al., 2007). Putman (2010) uses Admiral James Stockdale and other prisoners of war as powerful examples who refused for years, despite brutal actions of their Vietnamese captors, to release military secrets and to denounce their nation.

It is instructive to point out that each of these various examinations of moral courage, while different, are not incompatible. Integrating these views, we propose that moral courage can be represented as one's strength of character as proposed by Peterson and Seligman (2004). Yet, aspects of one's ethical personality have been described by Wood (2007) as a multidimensional system in which traits or character strengths are part of a more dynamic 'self-system' that can adapt and change across situations (Hill \& Roberts, 2010). Following Hannah and colleagues (e.g., Hannah, 
Avolio et al., 2011; Hannah et al., 2010), we propose that strengths of character in general, and moral courage in particular, should be viewed not as static traits, but as somewhat stable, yet malleable properties influenced within a SCT framework as individuals interact with their environment (Hill \& Roberts, 2010; Wood, 2007). Further, as a psychological property, moral courage is distinct from the courageous behavior it promotes, yet both are interdependent. Based on SCT, individuals will develop moral courage as they act or 'say no' and assess the impact of those choices and feedback from others. Miller has taken a similar position in stating that "courage is one of those things that can only be properly attained by doing it. To get courage, be courageous" (Miller, 2002: 26; see also Goud, 2005).

Building on earlier definitions of courage (e.g., Hannah, Avolio, et al., 2011; Kidder, 2005; Sekerka et al., 2009), we define moral courage as follows: 1) a malleable character strength, that 2) provides the requisite conation needed to commit to personal moral principles, 3 ) under conditions where the actor is aware of the objective danger involved in supporting those principles, 4) that enables the willing endurance of that danger, 5) in order to act ethically or resist pressure to act unethically as required to maintain those principles.

Further, observers will make attributions regarding an actor's level of moral courage based on situational factors and social norms. The socially accepted norms for what constitutes a morally courageous act have been called general courage, as opposed to self-attributed personal courage (Pury, Kowalski, \& Spearman, 2007). Yet, we know from SCT that personal and observer attributions are not independent. As individuals act they observe the reaction of others, who may be guided by social norms that distinguish what constitutes moral courage (Schwan, 2004; Worline, Wrzesniewski, \& Rafaeli, 2002). Based on the observers' reactions (e.g., providing accolades), one's internal attributions could reinforce increases in levels of moral courage. This suggests that through socialization processes what an individual perceives as personally courageous may over time come to align with the group's norm of general courage.

\section{Linking Moral Courage to Behavior}

Taking moral action requires an actor to know what the "right" judgment entails, as well as the fortitude to stand up in the face of adversarial conditions, which requires a sufficient level of moral courage, to overcome perceived threats while pursuing a moral purpose (Goud, 2005; Sekerka \& Bagozzi, 2007; Worline et al., 2002). Moral courage is thus critical in linking judgments to ethical action under such conditions (Kidder, 2005). Sekerka, Bagozzi, and Charnigo stated, "The strength of will is needed to face and resolve ethical challenges and to confront barriers that may inhibit the ability to proceed toward right action" and therefore is "a quality or attribute necessary for ethical behavior in organizational settings" (Sekerka et al., 2009: 566).

Viewing moral courage as a form of character strength suggests it provides an individual with the necessary psychological resources to enable sufficient agency when faced with an ethical challenge. Psychological resources such as moral courage are proposed to "loosen the hold that a negative emotion has gained on that 
person's mind and body by dismantling or undoing preparation for specific action" (Fredrickson, 2001: 222). Positive emotions thus work to counter the debilitating effects of negative emotions, which may otherwise narrow an individual's thinking, inhibiting him or her in taking appropriate action (Fredrickson, 2001). Moral courage provides the actor with the inner agency to engage to address the moral dilemma being faced, promoting action (Hannah \& Avolio, 2010; Sekerka \& Bagozzi, 2007).

Moral courage drives action not only when faced with those rare, tough, ethical issues, but also when extra-role or pro-social behaviors are required where risk is more minimal. For example, Kidder and Bracy (2001: 2) noted that "moral courage plays itself out daily, hourly, in the interstices of our lives" suggesting it is a constant force promoting socially desirable behavior. Along these lines, Woodard (2004) suggests that moral courage is more than just facing threat, and argues that important pro-social behaviors stemming from grace and nobility are expected to also be displayed by individuals with higher moral courage. Thus, we propose to test the following hypotheses:

Hypothesis la: Moral courage positively relates to follower ethical behavior.

Hypothesis 1b: Moral courage positively relates to follower pro-social behavior.

\section{Leadership and Follower Ethical Outcomes}

Exemplary leader behavior is important because leaders serve as role models for followers and set norms and expectations that influence the thoughts and behaviors of followers (Lester et al., 2010; Walker \& Henning, 2004). Research has shown that leader initiating structure and consideration behaviors can influence the ethical frameworks (i.e., formalism and utilitarianism) observed in followers (Schminke \& Wells, 1999; Schminke, Wells, Peyrefitte, \& Sebora, 2002). Leaders' levels of moral reasoning can also influence their followers' moral reasoning through role modeling, observation or instruction (Dukerich, Nichols, Elm, \& Vollrath, 1990). For example, when leader and follower levels of moral reasoning are congruent, research has shown that followers report higher levels of satisfaction and commitment along with lower turnover intentions (Schminke, Ambrose, \& Neubaum, 2005). The extent that leaders are seen as ethical has also been related to follower organizational commitment, extra effort, job satisfaction, performance, organizational citizenship behaviors (OCBs), voice, and their propensity to report issues and problems (Avey, Palanski, \& Walumbwa, 2011; Brown, Treviño, \& Harrison, 2005; Walumbwa \& Schaubroeck, 2009; Walumbwa, Mayer, Wang, Wang, Workman, \& Christensen, 2011).

Brown and Mitchell (2010) reviewed the constructs that have been empirically determined to be outcomes of exemplary leadership, including authentic, charismatic, ethical and transformational. Brown and Mitchell noted that charismatic and transformational leadership have been linked to "ethics-related outcomes," such as followers' perceptions of leader trust and fairness, as well as follower OCBs. Authentic leadership has also been shown to be positively related to follower OCBs and trust (Walumbwa, Wang, Wang, Schaubroeck, \& Avolio, 2010; Walumbwa, Luthans, Avey, \& Oke, 2011). Yet, besides ethics-related outcomes, surprisingly 
absent in this literature is empirical research that has examined linkages between ethical, authentic, transformational, or charismatic leadership and actual follower ethical behavior (Brown \& Mitchell, 2010). This is surprising, both because numerous authors have hypothesized these links (e.g., Avolio \& Gardner, 2005; Bass \& Steidlmeier, 1999; Brown \& Treviño, 2006), and it has been nearly two decades since Howell and Avolio (1992) first suggested that socialized charismatic/transformational leaders would promote follower ethical behavior.

\section{Authentic Leadership}

Authentic leadership is a multidimensional construct comprised of four dimensions: internalized moral perspective, self-awareness, relational transparency, and balanced processing (see Walumbwa et al., 2008, for a detailed discussion). Internalized moral perspective refers to higher levels of moral development and leader behaviors that are guided by internal moral standards and values as opposed to being driven by external pressure from peers, higher level leaders, or other social forces. When confronted with difficult ethical challenges, leaders with higher levels of moral perspective are expected to think more broadly and deeply about ethical issues (Werhane, 1999). Authentic leaders are also expected to behave in a more ethical manner as they tend to act in line with their internal values structures (Hannah, Lester, \& Vogelsang, 2005). This occurs because advanced moral constitution promotes concordant moral behavior (Blasi, 1980; Verplanken \& Holland, 2002). As a result, followers tend to attribute leaders' displays of consistent, values-based behaviors as being more 'authentic.'

Self-awareness refers to the extent to which a leader possesses accurate selfknowledge (Campbell, Trapnell, Heine, Katz, Lavallee, \& Lehman, 1996) and demonstrates he or she is cognizant of his or her impact on other people. Higher levels of self-awareness promote self-understanding of values, ideals and beliefs, as well as strengths and weaknesses. Self-awareness involves leaders using their knowledge about themselves to affect their agency (e.g., thinking, motivation and choice of behavior), which can enhance their capacity for leading and developing followers.

Relational transparency involves leader behaviors that promote positive relationships through disclosures and open sharing of information, including what constitutes the leader's true thoughts and feelings. Relational transparency is marked by openness, accountability and honesty between leaders and followers (Avolio \& Luthans, 2006), promoting clearer social exchanges where leaders and followers lay out what each expects from the relationship, and the inputs each are willing to provide, forming a more coherent psychological contract.

Finally, balanced processing involves openly and objectively analyzing available relevant information before coming to a conclusion or decision. Leaders who exhibit balanced processing solicit views from their followers, indicating their willingness to have their positions or beliefs challenged before coming to a decision. By soliciting views from followers, leaders can promulgate a better understanding with respect to abstract principles and ethical standards, and engage followers in ethical processes 
thereby raising their agency. Leaders demonstrating balanced processing also spend time trying to comprehend what caused problems and outcomes, thereby helping followers understand what should be attributed to internal and external causes of ethical behavior and performance (Gardner et al., 2005).

Although there is clearly some conceptual overlap, the four components of authentic leadership make it both theoretically (Avolio et al., 2004; Gardner et al., 2005) and empirically (Walumbwa et al., 2008; Walumbwa, Luthans et al., 2011) distinct from transformational leadership. Authentic leadership has also been both theoretically (Brown \& Treviño, 2006) and empirically (Brown et al., 2005) distinguished from ethical leadership, which tends to focus more on transactional forms of leader behaviors used to influence followers' ethical behaviors.

\section{Authentic Leadership and Follower Moral Courage and Behavior}

In their qualitative research of workplace (not necessarily moral) courage, Worline, Wrzesniewski, and Rafaeli (2002) brought attention to the importance of contextual influences such as role models in promoting courage in others. Further, research by Rothschild and Miethe (1999) reported that displays of moral courage in the form of whistle blowing were not sufficiently explained by individual differences and that one would also have to examine situational determinants to explain these actions. We propose leadership is one such critical determinant.

Based on SCT, we propose that authentic leaders will influence follower moral courage and subsequent behavior in two major ways. The first is the influence, through social learning and role modeling processes, behaviors associated with the four dimensions of authentic leadership (i.e., internalized moral perspective, self-awareness, relational transparency, and balanced processing) have on followers' moral courage. The second is the influence that authentic leaders have on the normative contexts followers operate in that can indirectly promote their moral courage and ethical outcomes.

Authentic Leadership Effects of Social Learning/Role-Modeling

Prior theorizing suggests that there are external social influences on moral courage that need to be taken into consideration. Kidder (2005: 214) suggested that, "modeling" is a particularly critical factor in the development of moral courage. Similarly, in their framework for courage development, Lester, Vogelgesang, Hannah, and Kimmey (2010) proposed that leaders, if seen as exemplary, can provide particularly effective role models in the development of courage in followers through their observations of and social learning from the leader. This is because moral exemplars would have a social learning effect on observers whereby they come to believe they too have the courage to successfully address difficult ethical challenges (Walker \& Henning, 2004). Yet, we are not aware of any research that has empirically assessed leadership as an antecedent to moral courage.

Leaders who are authentic are proposed to be especially attractive role models, making their behaviors prototypical and idealized in ways that team members come to identify with and replicate over time (Avolio et al., 2004). This is because attractive leaders provide followers a model that prompts goal-directed efforts toward 
mimicking the leader's behaviors (Lord \& Brown, 2004). Based on the foundational theory of authentic leadership, such leaders are expected to display behaviors that show others a pattern of consistency between the leader's moral and ethical values/ beliefs and the leader's subsequent actions, promoting confidence in the leader to do 'the right thing' and establishing a norm that followers should do the same.

From a social learning perspective (Bandura, 1977), when leaders signal that followers should stand up and act in line with their values, thus showing moral courage, and the leader consistently demonstrates similar behavior, members would be more likely to emulate such moral courage (Hannah et al., 2005). This process occurs as the authentic leader models the expected set of behaviors, and through social learning, followers develop scripts for courageous (Hannah et al., 2010; Sekerka et al., 2009) and ethical behaviors (Reynolds, 2006) that guide their actions when they may face similar moral dilemmas in the future (Gioia \& Poole, 1984).

Further, through social learning, as followers observe the leader, an exemplification effect can occur whereby the leader inspires certain values, beliefs, and other moral cognitive structures in followers through their demonstration and through transparent discussions about ethics (Avolio \& Gardner, 2005). When leaders inspire such values, it creates motivation for followers to reduce discrepancies between their own values and actions and those of the role model (Lord \& Brown, 2004). Indeed, prior research on self-concordance and self-verification motives (Carver \& Scheier, 1998; Verplanken \& Holland, 2002) has demonstrated that when cognitive structures related to specific values or ideals are salient, their salience creates a strong impetus to act in line with those values in order to establish coherence within the self and thereby maintain a positive self-evaluation. When followers are exposed to an authentic leader and these structures are activated, we expect that motivation to act in line with moral values and perspectives will promote moral courage to face fear and manifest beliefs into pro-social and ethical action (Blasi, 1980; Goud, 2005).

In sum, based on SCT, authentic leaders would be expected to inspire followers to seek to mimic their behaviors, and to model scripts for such exemplary behavior. Observing attractive role models also creates an exemplification effect, activating moral structures that promote self-concordant behaviors, creating the requisite courage to drive ethical and pro-social behaviors.

\section{Authentic Leadership Effects On Followers' Environments}

Building off our delineation between general and personal courage (Pury et al., 2007), prior research suggests that groups establish norms for what constitutes courageous behaviors (Schwan, 2004) and use those norms to influence other group members to display those behaviors (Worline et al., 2002). Hannah et al. (2010) argued that leaders can have a powerful influence on these normative processes operating within groups due to their salience as role models, their informational influences, and their authority to administer rewards or punishments (cf. Brown et al., 2005).

Authentic leaders engage their followers in transparent, open, balanced dialog concerning moral issues (Avolio et al., 2004; Gardner et al., 2005). We thus expect particularly strong informational influences to be operating between authentic leaders and their followers that make clear what types of behaviors are rewarded or 
demanded in the group, as well as what behaviors and temptations should be avoided and will be discouraged or punished. These strong informational cues would create a normative culture that promotes moral courage and subsequent moral action based on a sense of moral duty to the leader and the group.

Leaders seen as authentic by their followers also demonstrate a well-developed moral perspective and tend to work to create ethical organizational cultures that align with their moral perspective (Hannah et al., 2005). Ethical cultures not only communicate normative expectations as discussed previously, but also make desired values salient (Treviño \& Youngblood, 1990; Verschoor, 2003). Authentic leaders are specifically theorized to raise the salience and awareness of values and beliefs in the workplace (Gardner et al., 2005). Research has shown that when highly salient core values and beliefs are activated, it tends to prompt behavior in line with those beliefs (Blasi, 1980; Verplanken \& Holland, 2002), and central to the current study, promote moral courage to manifest those beliefs in action (Goud, 2005; Hannah \& Avolio, 2010).

Finally, we propose that authentic leaders' effects on the environment will promote moral agency in followers, the central component of SCT (see Figure 1, p. 558). Specifically, we suggest that authentic leaders will create a context where followers' are more likely to perceive that they can openly espouse their beliefs and manifest their beliefs in behaviors, expecting that those behaviors will be met with a positive reaction from the leader and others in the environment. Through establishing such a context, Ilies, Morgeson, and Nahrgang (2005) argued that authentic leaders will promote higher levels of personal agency in their followers (Kahn, 1990; Kernis \& Goldman, 2005). Ilies and colleagues argued this is partly because authentic leaders set the conditions for relational authenticity where both leader and followers feel at ease to disclose and act in accordance with their thoughts and ideals, which we expect will foster agentic moral courage and subsequent ethical behavior. Authentic leaders do this in part by including followers in ethical decision making and being balanced, allowing their decisions to be challenged and therefore more thoroughly discussed and understood (Avolio \& Gardner, 2005).

As personal agency is critical in promoting ethical action (Bandura, 1991), we suggest that when faced with ethical dilemmas, followers operating in a more open, transparent context punctuated with salient values will be more compelled to stand up and act in accordance with their beliefs despite pressures to do otherwise. Moral courage has thus been identified as inherently agentic (Sekerka et al., 2009), promoting engagement in ethical behaviors, and just as importantly, limiting moral disengagement which may otherwise occur when individuals seek to justify their omission of ethical, or commission of unethical acts (Bandura, 1999).

In sum, based on the SCT relationships denoted in Figure 1, authentic leaders serve a key role in followers' environments, influencing their moral courage directly, through social learning and role-modeling effects. Further, through the authentic contexts they create, authentic leaders both directly influence follower moral courage through normative and informational influences and the activation of values and other moral structures in followers; but such contexts also facilitate agentic moral courage in followers through transparency and engaging followers in open ethical 
dialog and sponsoring their self-determined behavior. Finally, through their various effects on follower moral courage, the effects of authentic leadership on follower behaviors is mediated. Thus, we propose to test the following set of hypotheses:

Hypothesis 2: Authentic leadership positively relates to follower moral courage.

Hypothesis 3a: Follower moral courage mediates the relationship between authentic leadership and follower pro-social behavior.

Hypothesis 3b: Follower moral courage mediates the relationship between authentic leadership and follower ethical behavior.

\section{STUDY METHODS}

\section{Participants and Procedures}

Participants were solicited from soldiers attending a training program at a major U.S. Army school in the United States. The program focused on three primary domains of development: intellectual (e.g., planning and tactician skills), military (e.g., raids and ambushes), and physical (e.g., obstacles courses and hand to hand combat). At Time 1, leaders and followers had been together within intact squads for approximately two months. At Time 1 followers provided demographic information and ratings of their squad leader's authentic leadership. Three to four months later each soldier was also rated on their demonstrated moral courage and their demonstrated ethical and pro-social behaviors by multiple peers $(n=162$ at both Time 1 and Time 2). Participants were 84 percent male, and their average age was 18.79 years $($ s.d. $=.94)$.

\section{Measures}

Authentic Leadership Behavior

At Time 1 soldiers rated their squad leaders' level of authentic leadership $(\alpha=.88)$ using the sixteen items from the Authentic Leadership Questionnaire or ALQ (Walumbwa et al., 2008). Sample items included, "My supervisor . . . seeks feedback to improve interactions with others" (self-awareness), "is willing to admit mistakes when they are made" (relational transparency), "makes difficult decisions based on high standards of ethical conduct" (internalized moral perspective), and "listens carefully to different points of view before coming to conclusions" (balanced processing). The response scale ranges from 0 (Not at all) to 4 (Frequently, if not always). The full survey scales can be obtained by going to www.mindgarden.com.

\section{Peer Moral Courage Ratings}

We proposed that moral courage is a fairly stable character strength (Peterson \& Seligman, 2004), providing the psychological resources needed to drive courageous behaviors when faced with moral dilemmas (Hannah et al., 2010). Moral courage therefore promotes fairly habitual actions across situations, which led Miller (2002) to argue it can be attributed by others through observation. Our measure of moral courage reflects general courage, social attributions of whether one is courageous based on whether their actions meet social norms for courage, versus idiosyncratic 
personal courage (Pury et al., 2007). Consistent with other research in military contexts using external ratings of moral courage (e.g., McGurk \& Castro, 2010), we developed three items to assess external peer ratings of moral courage anchored on a seven-point Likert scale ranging from 1 (never) to 7 (always). Using external ratings had the benefit of avoiding percept-percept bias, such that the authentic leadership and moral courage variables were not both rated by the follower. Further, using general courage ratings ensured that the courage attributed was recognized by others as courageous within this particular military context.

We obtained at least three peer ratings per soldier. These items captured observer reports of individuals' demonstrated moral courage based on three primary aspects proposed in prior literature, including the courage to overcome perceived threat to do what is right, even when faced with peer pressures; and the courage to correct others who behave inappropriately (Goud, 2005; Kidder, 2005), or as Kidder and Bracy (2001: 6) stated, moral courage to stand up in the face of both "ethical dilemmas and ethical wrongdoings." The measure also included an item based on the Stoic view of moral courage, the courage to say "no" and refrain from unethical action (Putman, 2010). The three items included, "This soldier . . . [p]ossesses the moral courage to correct fellow soldiers," "[a]dheres to regulations, even when faced with peer pressure to do otherwise," and "[d]emonstrates courage to do the right thing, even at personal cost."

Peer Ethical and Pro-Social Behavior Ratings

We collected peer ratings of followers' ethical and pro-social behaviors using a standardized institutional measure used by the military training center where this study was conducted. These measures were developed by the institution to reflect behaviors deemed ethical and pro-social in this particular environment and align with our definitions presented previously of ethical and pro-social behavior. This data were collected from the organization's archives. Every trainee at this center receives a combined peer rating approximately every five months, based on ratings from at least three of their squad members which are used to help guide their development. The ratings used in this study were taken four months after the authentic leadership ratings were collected.

Ethical behavior was measured with a five-item scale $(\alpha=.75)$ that asked peers to rate each follower on frequency of demonstrated ethical behavior and the restraint of unethical behavior when under social pressure. Responses were anchored on a seven-point Likert scale ranging from 1 (never) to 7 (always). Example items included, "To what extent does this soldier ... [d]emonstrate mature, responsible behavior," "[d]emonstrate good moral reasoning and judgment," and "[r]efrain from manipulating the system for personal gain."

Pro-social behavior was measured with a five-item scale $(\alpha=.74)$ that asked peers to rate each follower on frequency of demonstrated pro-social behavior. Responses were anchored on a seven-point Likert scale ranging from 1 (never) to 7 (always). Sample items include, "To what extent does this soldier ... [c] onsider the impact of his or her decisions and actions on others" and "[p]ut the good of the group ahead of his/her own self-interest." 


\section{RESULTS}

\section{Preliminary Analyses}

Because the moral courage measure was new we first tested its properties using a separate pilot sample of sixty-five soldiers from the same military base. Participants were 94 percent male, and their average age was 21.14 years (s.d. = 1.37). We conducted an exploratory factor analysis on the three items and results showed that a single factor emerged and explained 69 percent of the total variance in the items with an eigenvalue greater than 1.00. The Cronbach alpha $(\alpha)$ was .77. This factor structure was confirmed with the current dataset in which the results showed that a single factor emerged and explained 86 percent of the total variance in the items with an eigenvalue greater than 1.00. The $\alpha$ was .82, further suggesting that these items form a reliable scale.

Next we conducted a confirmatory factor analysis to confirm the higher-order factor structure of authentic leadership produced by earlier research. We compared a second order factor model in which items are loaded on their respective factors and the four factors then loading on a second-order latent authentic leadership factor, as proposed by Walumbwa et al. (2008), against several competing models as indicators of authentic leadership. Although all models displayed adequate fit, a significance test of chi-square difference revealed that the hypothesized second order factor model fit the data significantly better than all competing models (results of these analyses are available from the authors upon request). These results suggest that the four dimensions combine to create an overall core authentic leadership construct. Additionally, although the reliabilities of each of the four dimensions were all above .70, the overall combined reliability for authentic leadership significantly improved to an alpha of .88 .

Finally, because we procured multiple peer ratings of soldiers' moral courage and ethical and pro-social behaviors, we conducted a within-group agreement assessment $\left(r_{\mathrm{wg}(\mathrm{j})}\right.$; James, Demaree, \& Wolf, 1984) to assess the level of agreement among raters. The median within-group agreement were $.89, .84$, and .82 for moral courage, ethical behavior, and pro-social behavior, respectively, providing evidence of inter-rater agreement.

\section{Hypothesis Tests}

Table 1 shows the descriptive statistics, internal consistency reliabilities, and correlations among the study variables.

We utilized structural equation modeling (SEM) to test our hypotheses, as SEM allows for the estimation of relationships among constructs that are corrected for biases attributable to random error (Tomarken \& Waller, 2005) and provides the best balance of Type I error rates and statistical power (MacKinnon, Lockwood, Hoffman, West, \& Sheets, 2002). However, before testing our hypotheses, we examined a measurement model including all four variables (i.e., authentic leadership, moral courage, ethical and pro-social behaviors) to assess the relationships between latent variables and their indicators. We used items as indicators to ensure that we 
Table 1: Correlations Among the Study Variables

\begin{tabular}{lcccccc}
\hline \multicolumn{1}{c}{ Variable } & M & SD & $\mathbf{1}$ & $\mathbf{2}$ & $\mathbf{3}$ & $\mathbf{4}$ \\
\hline 1. Authentic leadership & 2.74 & .64 & $(.88)$ & & & \\
2. Moral courage & 5.23 & 1.23 & $18^{*}$ & $(.82)$ & & \\
3. Ethical behavior & 5.46 & .94 & $.29^{* *}$ & $.20^{* *}$ & $(.75)$ & \\
4. Pro-social behavior & 5.73 & .75 & $.32^{* *}$ & $.19^{*}$ & $.54^{* *}$ & $(.74)$ \\
\hline
\end{tabular}

Note. $\mathrm{n}=162 ; * p<.05\left(2\right.$-tailed); ${ }^{*} p<<.01$ (two-tailed)

obtained unbiased estimates (e.g., Bandalos, 2002; Little, Cunningham, Shahar, \& Widaman, 2002). This measurement model provided a good fit to our data $\left(\chi^{2}=\right.$ $696.45, d f=371, p<.01, \mathrm{CFI}=.93, \mathrm{GFI}=.95, \mathrm{IFI}=.94, \mathrm{RMR}=.05, \mathrm{RMSEA}=$ .06). The factor loadings and covariances were all significant (standardized loadings ranging $>.56$ ), evidencing convergent validity.

The SEM results testing our hypotheses are shown in Figure $2\left(\chi^{2}=719.48\right.$, $d f=373, p<.01, \mathrm{CFI}=.93, \mathrm{GFI}=.95, \mathrm{IFI}=.94, \mathrm{RMR}=.05, \mathrm{RMSEA}=.06)$. We allowed the disturbance terms of follower ethical and pro-social behavior to co-vary in order to provide a non-causal association between the two variables. As shown in Figure 2, moral courage is positively and significantly related to follower ethical behavior $(\beta=.28, p<.01)$ and pro-social behavior $(\beta=.21, p<.05)$. These results provide support for Hypotheses $1 \mathrm{a}$ and $1 \mathrm{~b}$, respectively. Hypothesis 2 which posited that authentic leadership would be positively related to follower moral courage was also supported $(\beta=.43, p<.01)$.

Hypotheses $3 \mathrm{a}$ and $3 \mathrm{~b}$ suggested that follower moral courage would mediate the influence of authentic leadership on followers' pro-social (H3a) and ethical behavior (3b). To test these hypotheses, we compared the fit of our hypothesized model shown in Figure 2 to two alternative models, each specifying partial versus full mediation. The first alternative model was similar to Figure 2 except we added a direct path from authentic leadership to follower pro-social behavior. This alternative model exhibited fit statistics almost identical to that of Figure $2\left(\chi^{2}=718.25, d f=372\right.$, $p<.01 ; \mathrm{CFI}=.93 ; \mathrm{GFI}=.95, \mathrm{IFI}=.94, \mathrm{RMR}=.05 ; \mathrm{RMSEA}=.06)$, with the dif-

Figure 2: Structural Equation Modeling Results

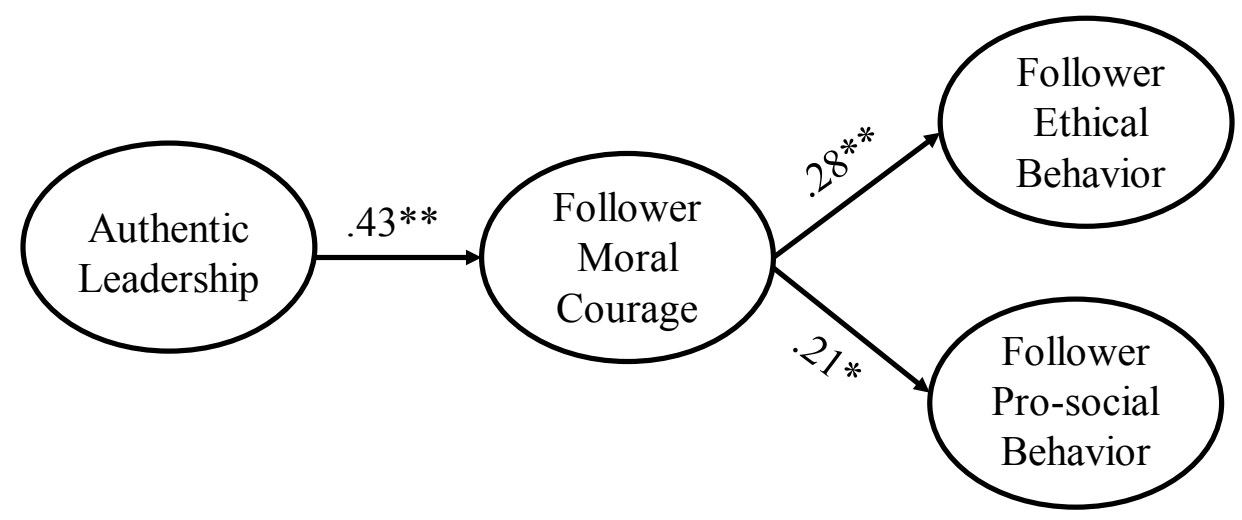

Note. The values are standardized path coefficients. ${ }^{*} \mathrm{p}<.05 ; * * \mathrm{p}<.01$ (two-tailed tests) 
ference in chi-square being non-significant $\left(\Delta \chi^{2}[1]=1.23\right.$, n.s $)$. However, the direct path from authentic leadership to follower pro-social behavior was non-significant.

The second alternative model was also similar to Figure 2, except we added a direct path from authentic leadership to follower ethical behavior. This alternative model also exhibited fit statistics almost identical to that of Figure $2\left(\chi^{2}=718.13\right.$, $d f=372, p<.01, \mathrm{CFI}=.93, \mathrm{GFI}=.95, \mathrm{IFI}=.94, \mathrm{RMR}=.05, \mathrm{RMSEA}=.06)$, with the difference in chi-square being non-significant $\left(\Delta \chi^{2}[1]=1.35, \mathrm{n} . \mathrm{s}\right)$. Importantly, the direct path from authentic leadership to follower ethical behavior was nonsignificant. Therefore, under rules of model parsimony, Figure 2 displays a more parsimonious model that achieves the best fit to the data. Hypotheses $3 \mathrm{a}$ and $3 \mathrm{~b}$ received support. Follower moral courage fully mediated the influence of authentic leadership on ethical as well as pro-social behavior. A Sobel (1982) test further confirmed these indirect effects (authentic leadership $\rightarrow$ moral courage $\rightarrow$ ethical behavior: $\mathrm{z}=2.12, p<.05$; authentic leadership $\rightarrow$ moral courage $\rightarrow$ pro-social behavior: $\mathrm{z}=2.09, p<.05)$.

\section{Exploratory Analysis}

Consistent with theory (e.g., Avolio et al., 2004; Gardner et al., 2005; Ilies et al., 2005) and preliminary empirical evidence (e.g., Hannah, Walumbwa, \& Fry, 2011; Walumbwa et al., 2008, 2010; Walumbwa, Luthans et al., 2011), in analyzing Hypotheses 1-3 we retained authentic leadership as a core construct comprised of its four factors. In this first test linking authentic leadership to moral courage and ethical behavior, we felt it was important to assess whether the four components of authentic leadership exert different influences on these outcomes.

First, we compared the correlations between each of the four dimensions with the three outcomes (i.e., moral courage, ethical and pro-social behavior) using Cohen and Cohen's (1983) test of correlation differences. The $t$-statistic (two-tailed) for the difference between each comparison of the authentic leadership dimensions were non-significant, indicating that there were no differential relationships. Finally, we ran a multiple regression analysis where we entered all of the four authentic leadership factors in the same regression equation to control for the effects of all the others on each outcome. These analyses also did not show any substantial significant differences in the coefficients, suggesting that the four components of authentic leadership combined to produce effects, but did not differentially affect outcomes.

\section{DISCUSSION}

Our study examined the antecedents and outcomes of moral courage, and the extent to which moral courage mediates the relationship between authentic leadership and follower ethical behavior and pro-social behavior. These measures were taken from three separate rating sources and lagged over a four month period. The study was conducted in a military field setting, where exemplary behavior is critical under the physical, psychological, and moral challenges inherent in more extreme contexts (Hannah, Uhl-Bien, Avolio, \& Cavarretta, 2009). Consistent with our predictions, 
our results suggest that moral courage is positively related to the extent to which followers behave ethically and restrain from unethical acts (Hypothesis 1a), and demonstrate positive social acts carried out to produce the well-being and integrity of others in the organization-pro-social behavior (Hypothesis 1b).

Our results further suggest that to promote moral courage, it is important that leaders demonstrate moral perspective, self-awareness, and establish transparency and openness with their followers-authentic leadership (Hypothesis 2). Finally, these findings suggest that moral courage is an important intervening mechanism linking authentic leadership to followers' pro-social (Hypothesis 3a) and ethical (Hypothesis 3b) behavior.

\section{Theoretical Implications}

Although interest in moral courage has grown, little is known about what promotes moral courage. This study answers calls for examining the processes that develop moral courage (e.g., Goud, 2005; Sekerka \& Bagozzi, 2007; Worline et al., 2002). Our findings demonstrated that leadership, in this case authentic leadership, may be an important factor in enhancing follower moral courage, through the mechanisms of SCT. These findings offer initial empirical evidence on which to build future research examining the development and outcomes of moral courage.

Further, our results linked moral courage to both externally rated ethical and prosocial behaviors in a dynamic field setting. The effects of authentic leadership on these outcomes were fully mediated through leaders' effects on followers' moral courage. These findings suggest not only that moral courage 'matters' in promoting exemplary behavior, but also introduces the potential mechanisms whereby leadership influences such ethical and pro-social behavior. Our findings suggest that moral courage is a critical intervening variable, and provides initial support for the theoretical arguments that moral courage is important to explaining the moral judgment-moral behavior linkage (Hannah, Avolio et al., 2011; Sekerka \& Bagozzi, 2007).

This is the first study to establish linkages between authentic leadership and follower ethical behaviors. These findings should encourage researchers to further refine the direct and mediated effects of leadership on ethical outcomes. Further, our results suggest there is synergy gained by the presence of all four factors of authentic leadership in predicting moral courage, ethical, and pro-social behaviors. These findings suggest that future research, extending beyond authentic leadership to other styles such as ethical leadership (Brown et al., 2005), should assess whether being seen as "moral" by followers is sufficient to produce positive effects, or whether a broader set of follower attributions bolster moral leaders' effects.

\section{Practical Implications}

Researchers have called for a deeper understanding of what promotes ethical behavior in the workplace (Treviño et al., 2006; Verschoor, 2003). We demonstrated that moral courage can be an important force in promoting such exemplary actions in followers, and that organizational leaders seen as authentic can promote such 
moral courage and action. Based on SCT, we hypothesized they do so through role modeling and the positive contexts they establish for followers that promote their moral courage.

Finally, the finding that follower moral courage positively related to follower ethical and pro-social behaviors suggests that training programs specifically designed to boost moral courage may be beneficial to organizations (e.g., Jonas, Boos, \& Brandstätter, 2007). Such programs may serve as a means for developing 'moral courage scripts,' that as noted earlier can help guide courageous action.

\section{Limitations and Future Directions}

There are limitations regarding this field study that suggest directions for future research. First, it has been suggested that extreme contexts create unique causation and contingencies affecting leadership processes (see Hannah et al., 2009 for review). Military contexts also have salient hierarchal systems and unique attraction and selection processes, which may have influenced the effects of leadership in the current study. Because of their formal status, for example, military leaders may be more salient as role models. Due to the potential costs of failure in military units, followers may also be more critical when rating the authenticity of their leaders, as compared to other samples. Yet, it is important to note that within this sample there was significant variance found in the variables that explained our findings. Additionally, there is a need to replicate and confirm our findings across a broader range of contexts and levels of organizations.

Second, the new measure of moral courage used here will require further construct validation work. Future research might also test moral courage using self-report measures that focus on the subjective experience of courage (i.e., personal courage) as opposed to attributions based on acts seen as courageous by others (i.e., general courage). Measures of subjective moral courage have recently been developed for use in organizational contexts (Hannah \& Avolio, 2010; Sekerka et al., 2009). It will be important for future research to compare self and external reports of moral courage in the same samples to assess their relative validity and effects.

Future research should investigate other mechanisms beyond moral courage that may help explain the authentic leadership-ethical behavior linkage, such as other components of moral conation (i.e., moral efficacy and moral ownership) proposed by Hannah and colleagues (Hannah, Avolio, et al., 2011; Hannah \& Avolio, 2010). Further, exposure to role models with higher levels of cognitive moral development (CMD; Kohlberg, 1981; Rest et al., 1999) may also promote higher CMD in observers through providing new moral perspectives (Dukerich et al., 1990). Authentic leaders with high levels of moral perspective who transparently discuss moral issues may play this role. Finally, leaders can prime values and ideals (Lord \& Brown, 2004) and ethical frameworks (Schminke \& Wells, 1999) in followers, suggesting that authentic leaders may influence the ways or "lenses" through which followers process ethical dilemmas, such as whether they use deontological/formalism, teleological/utilitarianism, or virtues perspectives. 
Finally, future research should assess whether negative forms of leadership, such as abusive leadership (Tepper, 2007), may negatively influence moral courage and other forms of moral conation, as well as subsequent ethical intentions and behaviors. It is quite likely that the mechanisms related to SCT we propose here would operate to reduce moral conation - i.e., poor role modeling and a climate that deters openness and transparency when facing ethical issues.

In sum, we believe that this study focusing on moral courage and its antecedents and outcomes is an important first step in examining more carefully what enables exemplary behaviors in followers. We hope these preliminary findings energize researchers to further the under-researched topic of moral courage as well as to better define the conditions and mechanisms that link leadership to positive outcomes of their followers and their organizations.

\section{ACKNOWLEDGEMENTS}

The authors would like to thank Professor Marshall Schminke and three anonymous reviewers for their guidance and numerous important recommendations to improve this manuscript.

\section{REFERENCES}

Avey, J. B., Palanski, M. E., \& Walumbwa, F. O. 2011. When leadership goes unnoticed: The moderating role of follower self-esteem on the relationship between ethical leadership and follower behavior. Journal of Business Ethics, 98: 573-82.

Avolio, B. J., \& Gardner, W. L. 2005. Authentic leadership development: Getting to the root of positive forms of leadership. Leadership Quarterly, 16: 315-38.

Avolio, B. J., Gardner, W. L., Walumbwa, F. O., Luthans, F., \& May, D. R. 2004. Unlocking the mask: A look at the process by which authentic leaders impact follower attitudes and behaviors. Leadership Quarterly, 15: 801-23.

Avolio, B. J., \& Luthans, F. 2006. The high impact leader: Moments matter for accelerating authentic leadership development. New York: McGraw-Hill.

Bandalos, D. L. 2002. The effects of item parceling on goodness-of-fit and parameter estimate bias in structural equation modeling. Structural Equation Modeling, 9: 78-102.

Bandura, A. 1977. Social learning theory. Englewood Cliffs, NJ: Prentice Hall.

1991. Social cognitive theory of moral thought and action. In W. M. Kurtines \& J. L. Gewitz (Eds.), Handbook of moral behavior and development, vol. 1: 45103. Hillsdale, NJ: Erlbaum.

1999. Moral disengagement in the perpetuation of inhumanities. Personality and Social Psychology Review, 33: 193-209.

2001. Social cognitive theory: An agentic perspective. Annual Review of Psychology, 52: 1-26.

Bass, B. M., \& Steidlmeier, P. 1999. Ethics, character, and authentic transformational leadership. Leadership Quarterly, 10: 181-218. 
Bebeau, M. J. 2002. The defining issues test and the four component model: Contributions to professional education. Journal of Moral Education, 31: 271-94.

Blasi, A. 1980. Bridging moral cognition and moral action: A critical review of the literature. Psychological Bulletin, 88: 1-45.

Brief, A. P., \& Motowidlo, S. J. 1986. Prosocial organizational behaviors. Academy of Management Review, 11: 710-25.

Brown, M. E., \& Mitchell, M. S. 2010. Ethical and unethical leadership: Exploring new avenues for future research. Business Ethics Quarterly, 20: 583-616.

Brown, M. E., \& Treviño, L. K. 2006. Ethical leadership: A review and future directions. Leadership Quarterly, 17: 595-616.

Brown, M. E., Treviño, L. K., \& Harrison, D. A. 2005. Ethical leadership: A social learning perspective for construct development and testing. Organizational Behavior and Human Decision Processes, 97: 117-34.

Campbell, J. D., Trapnell, P. D., Heine, S. J., Katz, I. M., Lavallee, L. F., \& Lehman, D. R. 1996. Self-concept clarity: Measurement, personality correlates, and cultural boundaries. Journal of Personality and Social Psychology, 70: 141-56.

Carver, C. S., \& Scheier, M. F. 1998. On the self-regulation of behavior. New York: Cambridge University Press.

Cohen, J., \& Cohen, P. 1983. Applied multiple regression/correlation analysis for the behavioral sciences (2nd ed.). Hillsdale, NJ: Erlbaum.

Dukerich, J. M., Nichols, M. L., Elm, D. R., \& Vollrath, D. A. 1990. Moral reasoning in groups: Leaders make a difference. Human Relations, 43: 473-93.

Fredrickson, B. L. 2001. The role of positive emotions in positive psychology: The broadenand-build theory of positive emotions. American Psychologist, 56: 218-26.

Gardner, W. L., Avolio, B. J., Luthans, F., May, D. R., \& Walumbwa, F. O. 2005. “Can you see the real me?" A self-based model of authentic leader and follower development. Leadership Quarterly, 16: 343-72.

Gioia, D. A., \& Poole, P. P. 1984. Scripts in organizational behavior. Academy of Management Review, 9: 449-59.

Goud, N. H. 2005. Courage: Its nature and development. Journal of Humanistic Counseling, Education, and Development, 44: 102-16.

Hannah, S. T., \& Avolio, B. J. 2010. Moral potency: Building the capacity for characterbased leadership. Consulting Psychology Journal, 62: 291-310.

Hannah, S. T., Avolio, B. J., \& May, D. R. 2011. Moral maturation and moral conation: A capacity approach to explaining moral thought and action. Academy of Management Review, 36.

Hannah, S. T., Lester, P. B., \& Vogelgesang, G. 2005. Moral leadership: Explicating the moral component of authentic leadership. In W. L. Gardner, B. J. Avolio, \& F. O. Walumbwa (Eds.), Authentic leadership and practice: Origins, effects, and development: 43-82. Amsterdam: Elsevier. 
Hannah, S. T., Sweeney, P. J., \& Lester, P. B. 2010. The courageous mindset: A dynamic personality system approach to courage. In C. Pury \& S. Lopez (Eds.), The psychology of courage: Modern research on an ancient virtue: 125-48. Washington, DC: American Psychological Association.

Hannah, S. T., Uhl-Bien, M., Avolio, B. J., \& Cavarretta, F. 2009. A framework for examining leadership in extreme contexts. Leadership Quarterly, 20: 897-919.

Hannah, S. T., Walumbwa, F. O., \& Fry. J. 2011. Leadership in action teams: Team leader and members' authenticity, authenticity strength, and performance outcomes. Personnel Psychology, 64: 771-801.

Hill, P. L., \& Roberts, B. W. 2010. Propositions for the study of moral personality development. Current Directions in Psychological Science, 19: 380-83.

Howell, J. M., \& Avolio, B. J. 1992. The ethics of charismatic leadership: Submission or liberation? Academy of Management Executive, 6: 43-54.

Hunter, J. D. 2003. The death of character. New York: Basic Books.

Ilies, R., Morgeson, F. P., \& Nahrgang, J. D. 2005. Authentic leadership and eudaemonic well-being: Understanding leader-follower outcomes. Leadership Quarterly, 16: 373-94.

James, L. R., Demaree, R. G., \& Wolf, G. 1984. Estimating within-group inter-rater reliability with and without response bias. Journal of Applied Psychology, 69: 85-98.

Jonas, K., Boos, M., \& Brandstätter, B. (Eds.). 2007. Training moral courage: Theory and practice. Göttingen, Germany: Hogrefe.

Kahn, W. A. 1990. Psychological conditions of personal engagement and disengagement at work. Academy of Management Journal, 33: 692-724.

Kernis, M. H., \& Goldman, B. M. 2005. From thought and experience to behavior and interpersonal relationships: A multicomponent conceptualization of authenticity. In A. Tesser, J. V. Wood, \& D. Stapel (Eds.), On building, defending and regulating the self: A psychological perspective: $31-52$. New York: Psychology Press.

Kidder, R. M. 2005. Moral courage. New York: William Morrow.

Kidder, R. M., \& Bracy, M. 2001. Moral courage: A white paper. Camden, MA: Institute for global ethics.

Kohlberg, L. 1981. The philosophy of moral development. San Francisco: Harper \& Row.

Lester, P. B., Vogelgesang, G., Hannah, S. T., \& Kimmey, T. 2010. Developing courage in followers: Theoretical and applied perspectives. In C. Pury \& S. Lopez (Eds.), The psychology of courage: Modern research on an ancient virtue: 210-45. Washington, DC: American Psychological Association.

Little, T. D., Cunningham, W. A., Shahar, G., \& Widaman, K. F. 2002. To parcel or not to parcel: Exploring the question, weighing merits. Structural Equation Modeling, 9: $151-73$.

Lord, R. G., \& Brown, D. J. 2004. Leadership processes and follower self-identity. Hillsdale, NJ: Lawrence Erlbaum. 
MacKinnon, D. P., Lockwood, C. M., Hoffman, J. M., West, S. G., \& Sheets, V. 2002. A comparison of methods to test mediation and other intervening variables effects. Psychological Methods, 7: 83-104.

McGurk, D., \& Castro, C. A. 2010. Courage in combat. In C. Pury \& S. Lopez (Eds.), The psychology of courage: Modern research on an ancient virtue: 167-85. Washington, DC: American Psychological Association.

Miller, W. I. 2002. The mystery of courage. Cambridge, MA: Harvard University Press.

Monin, B., Pizarro, D. A., \& Beer, J. S. 2007. Deciding versus reacting: Conceptions of moral judgment and the reason-affect debate. Review of General Psychology, 11: 99-111.

Nussbaum, M. 1992. Tragedy and self-sufficiency: Plato and Aristotle on fear and pity. In J. Annas (Ed.), Oxford studies in ancient philosophy: 107-60. New York: Oxford Press.

Peterson, C., \& Seligman, M. E. P. 2004. Character strengths and virtues: A handbook and classification. New York: Oxford University Press.

Pury, C., Kowalski, R., \& Spearman, J. 2007. Distinctions between general and personal courage. The Journal of Positive Psychology, 2: 99-114.

Putman, D. 2010. Philosophical roots of the concept of courage. In C. Pury \& S. Lopez (Eds.), The psychology of courage: Modern research on an ancient virtue: 9-22. Washington, DC: American Psychological Association.

Rest, J. R., Narvaez, D., Bebeau, M. J., \& Thoma, S. J. 1999. Postconventional moral thinking: A neo-Kohlbergian approach. Mahwah, NJ: Erlbaum.

Reynolds, S. J. 2006. A neurocognitive model of the ethical decision-making process: implications for study and practice. Journal of Applied Psychology, 91: 737-48.

Rothschild, J., \& Miethe, T. D. 1999. Whistle-blower disclosures and management retaliation. Work and Occupations, 26: 107-28.

Schminke, M., Ambrose, M. L., \& Neubaum, D. O. 2005. The effect of leader moral development on ethical climate and employee attitudes. Organizational Behavior and Human Decision Making Processes, 97: 135-51.

Schminke, M., \& Wells, D. 1999. Group processes and performance and their effects on individuals' ethical framework. Journal of Business Ethics, 18: 367-81.

Schminke, M., Wells, D., Peyrefitte, J., \& Sebora, T. C. 2002. Leadership and ethics in work groups: A longitudinal assessment. Group and Organization Management, 27: 272-93.

Schwan, G. 2004. Civil courage and human dignity: How to regain respect for the fundamental values of western democracy. Social Research, 71: 107-16.

Sekerka, L. E., \& Bagozzi, R. P. 2007. Moral courage in the workplace: Moving to and from the desire and decision to act. Business Ethics: A European Review, 16: $132-49$.

Sekerka, L. E., \& Bagozzi, R. P., \& Charnigo, R. 2009. Facing ethical challenges in the workplace: Conceptualizing and measuring professional moral courage. Journal of Business Ethics, 89: 565-79. 
Sobel, M. E. 1982. Asymptotic confidence intervals for indirect effects in structural equation models. In S. Leinhardt (Ed.), Sociological methodology: 290-312. Washington, DC: American Sociological Association.

Tenbrunsel, A. E., \& Smith-Crowe, K. 2008. Ethical decision making: Where we've been and where we're going. Academy of Management Annals, 2: 545-607.

Tepper, B. 2007. Abusive supervision in work organizations: Review, synthesis, and research agenda. Journal of Management, 33: 261-89.

Tomarken, A. J., \& Waller, N. G. 2005. Structural equation modeling: Strengths, limitations, and misconceptions. Annual Review of Clinical Psychology, 1: 31-65.

Treviño, L. K., Weaver, G. R., \& Reynolds, S. J. 2006. Behavioral ethics in organizations: A review. Journal of Management, 32: 951-90.

Treviño, L. K., \& Youngblood, S. A. 1990. Bad apples in bad barrels: A causal analysis of ethical decision making behavior. Journal of Applied Psychology, 75: 447-76.

Verplanken, B., \& Holland, R. W. 2002. Motivated decision making: Effects of activation and self-centrality of values on choices and behavior. Journal of Personality and Social Psychology, 82: 434-47.

Verschoor, C. C. 2003. Eight ethical traits of a healthy organization. Strategic Finance, 85: $20-30$.

Walker, L. J., \& Henning, K. H. 2004. Differing conceptions of moral exemplarity: Just, brave, and caring. Journal of Personality and Social Psychology, 86: 629-47.

Walumbwa, F. O., Avolio, B. J., Gardner, W. L., Wernsing, T. S., \& Peterson, S. J. 2008. Authentic leadership: Development and analysis of a multidimensional theorybased measure. Journal of Management, 34: 89-126.

Walumbwa, F. O., Luthans, F., Avey, J., \& Oke, A. 2011. Authentically leading groups: The mediating role of positivity and trust. Journal of Organizational Behavior, 32: 43-24.

Walumbwa, F. O., Mayer, D. M., Wang, P., Wang, H., Workman, K., \& Christensen, A. L. 2011. Linking ethical leadership to employee performance: The roles of leadermember exchange, self-efficacy, and organizational identification. Organizational Behavior and Human Decision Processes, 115: 204-13.

Walumbwa, F. O., \& Schaubroeck, J. 2009. Leader personality traits and employee voice behavior: Mediating roles of ethical leadership and work group psychological safety. Journal of Applied Psychology, 94: 1275-86.

Walumbwa, F. O., Wang, P., Wang, H., Schaubroeck, J., \& Avolio, B. J. 2010. Psychological processes linking authentic leadership to follower behaviors. Leadership Quarterly, 21: 901-14.

Werhane, P. 1999. Moral imagination and management decision making. New York: Oxford.

Wood, D. 2007. Using PRISM to compare the explanatory value of general and rolecontextualized trait ratings. Journal of Personality, 75: 1103-26.

Woodard, C. R. 2004. Hardiness and the concept of courage. Consulting Psychology Journal: Research and Practice, 56: 173-85. 
Woodard, C. R., \& Pury, C. L. 2007. The construct of courage: Categorization and measurement. Consulting Psychology Journal: Research and Practice, 59: 13547.

Worline, M. C., Wrzesniewski, A., \& Rafaeli, A. 2002. Courage and work: Breaking routines to improve performance. In R. Lord, R. Klimoski, \& R. Kanfer (Eds.), Emotions at work: 295-330. San Francisco: Jossey-Bass. 